\title{
Prospects for Experimental Philosophical Logic
}

\author{
Jeremiah Joven Joaquin*
}

Received: 24 April 2018 / Accepted: 19 November 2018

Abstract: This paper focuses on two interrelated issues about the prospects for research projects in experimental philosophical logic. The first issue is about the role that logic plays in such projects; the second involves the role that experimental results from the cognitive sciences play in them. I argue that some notion of logic plays a crucial role in these research projects, and, in turn, the results of these projects might inform substantive debates in the philosophy of logic.

Keywords: Applied logic; descriptive models; experimental philosophical logic; normative models; philosophy of logic; prescriptive models; psychology of reasoning; pure logic.

\section{Introduction}

Over the years, there has been a steady growth of research projects, which fall under what has been dubbed as experimental philosophical logic (Ripley 2016). ${ }^{1}$ Like most sub-areas of philosophy that experienced the

1 The following works might arguably be classified under this heading: (Alxatib and Pelletier 2011), (Bonini et al. 1999), (Brauner 2014), (Cobreros et al. 2012),

* De La Salle University

- Department of Philosophy, De La Salle University, 2401 Taft Avenue, 0922 Manila, Philippines

$\bowtie$ jeremiah.joaquin@dlsu.edu.ph

(C) The Author. Journal compilation (c) The Editorial Board, Organon F.

This article is distributed under the terms of the Creative Commons Attribution-NonCommercial 4.0 International Public License (CC BY-NC 4.0). 
experimental turn, ${ }^{2}$ experimental philosophical logic seeks to employ not only the available tools and methods of traditional philosophy, but also the tools and data from the experimental cognitive sciences (especially, the psychology of reasoning) to aid philosophical inquiries into the nature of logic itself. Furthermore, some experimentally-inclined philosophers of logic envision that such a sharing of resources might lead to a more fruitful study of human cognition and reasoning (Dutilh Novaes 2012; Rips 2008; Stenning and Van Lambalgen 2008; and van Benthem 2008).

In this paper, I explore the prospects for this kind of project. In particular, I focus on two interrelated issues about the relationship between logic and the philosophy of logic, on the one hand, and the experimental results from the cognitive sciences, on the other. I cash out these issues in terms of the respective roles that logic and experiment play in the research projects in experimental philosophical logic. The first issue centers on the role of pure logic and the philosophy of logic in these projects; the second focuses on the role of these experimental results in pure logic and the philosophy of logic.

I argue for two points. First, while there are reasons to think that logic plays a crucial role in experimental philosophical logic, it is debatable whether such experimental results would impact research projects in pure logic. Though this is the case, these results could still offer some empirically backed-up data that could inform substantive debates in the philosophical logic. ${ }^{3}$

(Dutilh Novaes 2012), (Geurts and van Der Slik 2005), (Ghosh, Meijering, and Verbrugge 2014), and (Ripley 2011).

2 Proponents of this experimental turn argue that philosophers should "proceed by conducting experimental investigations of the psychological processes underlying people's intuitions about central philosophical issues" (Knobe and Nichols 2007, 3).

3 As was pointed out by a referee of this journal, the phrase, "philosophical logic" is ambiguous. It might refer to logic as applied to philosophy; for example, the use of possible world semantics in analyzing modality. [See (Sider 2010) for other ways that logic might be applied to philosophy.] It might also refer to philosophical issues about logic; for example, the issue about the nature of logical consequence. [See (Read 1995) for discussions on other philosophical issues in logic.] For our purposes, we follow (Restall and Russell 2012), and take philosophical logic as "the study of 
The next section is scene-setting. I discuss, in broad strokes, what research projects in experimental philosophical logic are deemed to be, and how they are to be understood vis-à-vis works in pure logic and applied logic. The third section centers on the role of logic in experimental philosophical logic. I explore two possible roles for logic: a normative role, which depicts logic as a body of principles for correct reasoning; and, a descriptive role, which depicts logic as a way of modeling some target cognitive or reasoning phenomena. I show some criticisms against these depictions, and suggest that a way to address these criticisms might be by adding a prescriptive role for logic. ${ }^{4}$

The fourth section focuses on the issue about the role of experimental results in logic. I discuss two negative views due to L. Jonathan Cohen (1981) and Gilbert Harman (1986). I reply that though experimental results might not substantially affect work in pure logic, they could nonetheless impact work in the philosophy of logic. Finally, the final section explores two strands of work in experimental philosophical logic as case studies. I discuss first the work of Catarina Dutilh Novaes on the role of formal logic in the psychology of cognitive biases; second, I discuss the growing research on the logic and psychology of vagueness. ${ }^{5}$ I conclude with some remarks about the importance of these works on the philosophy of logic.

logic - itself understood broadly — and its applications, pursued to philosophical ends." As such, for our purposes, we use "philosophy of logic" and "philosophical logic" interchangeably. Note, however, that this usage deviates from (Burgess 2009), (Cook 2001), (Jacquette 2007), and (Sainsbury 2001).

${ }_{4}$ Incidentally, the normative, descriptive, and prescriptive roles are already acknowledged in the psychology of reasoning literature [see e.g. (Bell, Raiffa, and Tversky 1988), (Evans and Over 1996), and (Stanovich 1999)]. Note, however, the nature of these roles is not uncontroversial.

5 The literature for these two case studies is vast. Since we will just explore them for illustrative purposes, we will limit the discussion to the following works. For the first case, we focus on (Dutilh Novaes and Reck 2017) and (Dutilh Novaes 2012, 2015). For the second case, we focus on (Alxatib and Pelletier 2011), (Bonini et al. 1999), (Cobreros et al. 2012), and (Ripley 2011). 


\section{Pure and applied logic}

Research works in logic fall under two broad categories (Ripley 2016; Priest 2005). ${ }^{6}$ There are works in pure logic and there are works in applied logic. Works in pure logic are deeply abstract and might be classified as works in some sub-branch of pure mathematics. These works are "explorations of the properties and relations occupied by logical systems in themselves, without attending to any particular use they may or may not have" (Ripley 2016, 524). Typically, works in pure logic center on the construction and investigation of different formal systems along with their respective proof and model theories, and their respective completeness and soundness theorems. These are pursued for their own sake with no particular application in mind.

Works in applied logic, on the other hand, are more concrete, and could be seen as works that use logic for a specific purpose. Examples of such works abound. The Quine-McCluskey algorithm, for example, which is a method for determining the minimum number of Boolean functions in a given logical system, was employed in computer technology to simplify electronic circuits (Roth and Kinney 2014). The Lambek Calculus, a logic developed to analyze hierarchy of types, on the other hand, was employed in the analysis of certain grammatical structures of some natural languages (Priest 2005, sec. 12.2). Though the application of logic in these areas is of interest, we shall not be concerned with this sense of applied logic in this paper; what we shall be concerned with, rather, is arguably the canonical application of logic. Furthermore, we will look at how this application connects with one important issue in the philosophical logic, viz. whether there is one true logic.

The canonical application of logic is, arguably, in the analysis of reasoning (Priest 2005, sec. 12.4). ${ }^{7}$ It is the science that inquires about what follows from what-i.e. what conclusion validly follows from a given set of

6 I am aware that there are other ways of classifying works in logic. But this broad classification of pure and applied logics would suffice for my purposes here.

7 As was pointed out by this journal's referee, this point is controversial. As we will see later in sec. 3 , some theorists suggest a distinction between logic as concerned 
premises. ${ }^{8}$ And like many other types of scientific inquiry, logic is couched in a highly mathematical, formal language. This formalization, in turn, provides an account of validity.

But there is a complication here. As it turns out, there are many logics. There are many formal systems of logic, each of which offers a different account of validity. For example, classical logic provides a notion of validity in terms of the impossibility of the conclusion to be false while the premises are true. Intuitionistic logic, on the other hand, gives an account of validity in terms of constructive proofs from a given set of premises to a conclusion. Some paraconsistent logics offer still another different conception of validity in terms of some type of relevance relation between premises and conclusions (Beall and Restall 2006). And there are more. In fact, there is a host of other pure logics, each of which offers a different formal account of validity. Some of these formal accounts cohere with one another; others conflict with each other. This plurality of logics leads to a central issue in discussions in the philosophy of logic.

One central issue in the philosophy of logic precisely amounts to the issue of whether there is only one true logic, or whether there are many, equally true logics (Beall and Restall 2006; Russell 2008). By "logic" we mean a formal theory of consequence (i.e. deductive validity). By "true logic" we mean the correct account of logical consequence. Monists, like Priest (2005), argue that there can only be one true account of logical consequence. Pluralists, like Beall and Restall (2006), on the other hand, argue that there are many, equally true logics. ${ }^{9}$

The issue between pluralists and monists about logical consequence is a broad and delicate philosophical issue. It is broad in that the debate involves a lot of aspects of logic. It is not only concerned about the nature of logic itself, but also of the nature of logical constants, logical truths, and logical consequence. It is delicate in that what is at stake is the core of

about deductive validity as opposed to reasoning per se, see e.g. (Harman 1986); for a reply, see (Field 2009) and (Sainsbury 2002).

8 Throughout this paper, we will be concerned with the notion of deductive validity and not inductive validity.

9 Perhaps, there is a third, ultra negative view, logical nihilism, which tells us that there's no such thing as a logic (Russell 2017). 
reasoning itself. If it turns out that monism is right, then there is only one correct way of reasoning. If it turns out the pluralism is right, then there is more than one way of reasoning correctly.

There is no fast way of adjudicating between pluralism and monism. But the issue could be made tractable by translating the issue into the question of the adequacy of a logical theory to account for its data. Given the canonical application of logic, a logical theory ought to provide an account of correct reasoning. This account, however, need not be a general model of reasoning; it might just be about a particular piece of reasoning. To check whether some logical theory is correct, we need to check whether it adequately accounts for the data it purports to explain.

Consider, for example, how some logical theory explains how we reason about vagueness. Take any logical theory that models vagueness, for example, Lukasiewicz's three-valued logic, L3, or Priest's Logic of Paradox, LP. Check whether the proffered logical theory adequately explains not only the target phenomenon, but also the sorites paradox, which results from it. ${ }^{10}$

This strategy connects up nicely with the pluralism/monism debate. If there are two or more logical theories adequately explain how we reason about vagueness, then, perhaps, all things being equal, taking a pluralist view about the logic of vagueness is the right way to go. On the other hand, if only one theory is adequate, then, perhaps, monism is the right view. If none of the current theories accounts for vagueness, however, then we should perhaps consider other logics to account for it.

Determining the adequacy of a given logical theory, however, is not a straightforward matter, and has been a subject of much debate. Some theorists have suggested that, at the very minimum, logical theories should provide an accurate formalization of the target phenomenon in that the relevant aspects of the target phenomenon are formalized appropriately. Others put premium to the informativeness of the proffered theory. A given logical theory should be able to provide a non-circular, non-trivial explanation of the target phenomenon. But whatever the criterion for adequacy might be, a logical theory must be able to explain its data. That is, it must be able to explain the piece of reasoning it aims to account for. In a way,

10 For a useful introduction to the various logics of vagueness, see (Williamson 1995) and (Smith 2008). 
one might argue that the criteria for adequacy of a given logic should be based on the same set of criteria used in the sciences, like physics, chemistry, and biology, viz., simplicity, fruitfulness, explanatory power, etc. ${ }^{11}$

Treating different logics as scientific theories naturally leads us to the question about the importance of experimental data to logic. The hard sciences give importance to experimental data as they are employed as a test to either confirm or disconfirm a proposed physical theory. For example, Einsteinian relativity theory was confirmed by some set of experimental data due to Arthur Eddington; much in the same way that the phlogiston theory was disconfirmed by some other set of experimental data concerning heat and its effect to molecular movement. But even if we grant that experimental data are important in these fields, is this true of theories of logic as well? Are experimental data important to logic? Experimentally-minded philosophers and logicians think that this is so.

Like many philosophers who advocate an experimental turn in philosophy, experimentally-minded philosophers and logicians think that experimental data are important to logic, especially, to the philosophy of logic, since they could serve as checks on philosophical (logical) intuitions; and, as a test of a philosophical (logical) theory's empirical claims (Chalmers 2009, 2007). ${ }^{12}$ For example, as experimental moral philosophers test whether our actual moral intuitions are consistent with the claims of some moral theory experimental logicians test whether our actual judgments and reasoning processes are best explained by some logical theory. This implies, then, that experimental data might serve as a check for the empirical adequacy of a given logical theory. Thus, given that logical theories aim to account for certain forms of reasoning, experiments could be set up to test whether such theories actually provide accurate descriptions of them. ${ }^{13}$

11 See, for example, the discussion of Alfred Tarski's and Rudolf Carnap's criteria for formal adequacy in (Dutilh Novaes and Reck 2017); for a discussion of Carnap's views of definitional adequacy, see (Chalmers 2012, chap. 1); for a discussion of the 'science-like' mechanisms for theory-selection in logic, see (Priest 2014; 2005, chap. $8)$.

12 Permission to cite these two references was granted by David Chalmers.

13 Works cited in footnote 1 exemplify this. 
To illustrate, let us take classical logic as our target formal system, and check whether its inference rules hold in ordinary reasoning. One controversial inference rule in classical logic is explosion: from a contradiction, anything follows. Experimentally-minded logicians might want to test whether this principle holds in actual reasoning. They may do this by conducting experiments to test a subject's inferential responses to contradictory information.

For example, subjects might be tasked to deduce certain conclusions from a given set of facts which include contradictory information. Suppose the set includes the following: "Amanda is a grade 6 student;" "Amanda is 11 years old;" "If Amanda is a grade 6 student, then she is smart;" and "Amanda is not 11 years old." Experimenters could then ask their subjects whether the following conclusions, "Amanda is smart" and "Manila is in the Philippines," could be validly inferred from the set. If the subjects answer "Yes" to both, then we could say that they are abiding by the principles of classical logic. ${ }^{14}$ If they only answer "Yes" to the former, then we could say that they are employing a different, non-explosive logic in making their inferences; this, perhaps, is a kind of paraconsistent, relevant logic. ${ }^{15}$

As such, in this picture, experimental data is employed to test and validate whether actual reasoners employ some non-classical logical device in their inferences. Furthermore, the logical device itself would serve as an explanation of why reasoners make inferences the way they do.

Experimental philosophical logic works by exploring two important features: (1) that a formal model can account for a target phenomenon; (2) that the target phenomenon being modeled is itself amenable to experimental exploration. The first feature implies that the target phenomenon,

14 This is so since, via modus ponens, from "If Amanda is a grade 6 student, then Amanda is smart" and "Amanda is a grade 6 student," we could validly infer that "Amanda is smart." And via explosion, the conclusion, "Manila is in the Philippines" could be validly inferred from the contradictory premises: "Amanda is 11 years old" and "Amanda is not 11 years old."

15 This is so since, though explosion is invalid in a paraconsistent logic, it still permits certain valid inferences so long as they do not include contradictory premises as part of the inference.

Organon F 26 (2) 2019: 265-286 
be it linguistic behavior, social communicative behaviors, etc., can be modeled by a given formal system. The second feature, on the other hand, implies that there is an experimental way to validate (or verify) whether the target phenomenon is indeed modeled by the formal theory (Ripley 2016). The combination of these two aspects will tell us whether a given logical theory is empirically adequate; it would also tell us whether the theory is a good scientific explanation of a piece of reasoning.

One may notice, however, that there are key assumptions to this experimental approach to philosophical logic. On the one hand, it treats logical theories not just as normative theories of how reasoners ought to think, but as descriptive theories of how people actually think. On the other hand, it treats experimental data as genuine tests for the adequacy of logical theories. One might question these assumptions; and thus might put into question the whole enterprise of an experimental approach to philosophical logic. To question the first assumption is to question the role of logic in experimental philosophical logic; to question the second is to question the role of experimental data in the enterprise. We will look at these issues in the following two sections.

\section{Three roles for logic: descriptive, normative, and prescriptive}

One issue that can be raised about projects in experimental philosophical logic has something to do with the role of logic in these projects. What role, if any, does logic play in experimental philosophical logic? There are two prominent views about the role of logic found in the literature: a normative role and a descriptive role (Stich 1990, 13-16).

On the normative view, a logical theory is taken as a body of reasoning principles that serves as the norms for correct reasoning. Logical principles function as a kind of permission inference-tickets; i.e. as rules that tell us that from a given premise, such and such a conclusion follows. Alternatively, they can be seen as rules of inference that specify the conditions for validity; i.e. as structural rules that tell us that if some natural language argument is an instance of such and such an argument structure, then it is 
valid. For example, classical logic has a disjunction-introduction rule that tells us that from any proposition, $\mathrm{P}$, one could infer the disjunction, $\mathrm{P}$ or Q. Thus, from the premise "Hazel is loving" we could validly infer that "Either Hazel is loving or Hazel is sweet." Alternatively, since the argument, "Hazel is loving; therefore, either Hazel is loving or Hazel is sweet" is an instance of the disjunction-introduction rule, we could conclude that such an argument is valid.

On the descriptive view, a logical theory is taken as a model (i.e. a formal description) of a given reasoning phenomena. According to this view, logic is a kind of zoological study whose primary task is to document, formalize, and categorize various types of reasoning in an appropriate logical system. For example, arguments, like "If Candice is 6 years old, then Candice is no longer a baby; Candice is 6 years old; thus: Candice is no longer a baby" is piece of valid reasoning. Arguments with same structure preserve truth from premise to conclusion. The task then of a logical theory is formalize this structure into something known as modus ponens, "If $\mathrm{P}$, then Q; P; therefore, Q." This formalized structure would, then, be treated as a cognitive artifact ${ }^{16}$ which would be catalogued and indexed to some logical system.

Each of these roles, however, seems to imply certain worries. Treating logic as a system that provides norms for correct reasoning seems to overestimate the capacity of actual (human) reasoners. That is, taken by its normative role, experimental philosophers of logic might evaluate reasoners in terms of some standard logic - usually, in terms of classical logic; since experimental data have shown that actual reasoners do not always follow the norms of this standard logic, these philosophers might make the conclusion that human beings are generally just poor reasoners, or are always prone to systematic errors (Evans and Over 1996, 4). This is worrisome because it might be the case that some people employ a different kind of logic that does not abide by the principles of classical logic.

Treating logic as descriptive models of human reasoning, on the other hand, seems to deny the normative force of logical principles. Focusing mainly on the descriptive role of logic, experimental philosophers of logic

16 A cognitive artifact is defined as a physical extension or manifestation of our cognitive abilities (Dutilh Novaes 2012). 
might be overwhelmed by the different types of reasoning deployed by ordinary reasoners such that they will just take the data as they come, and catalogue them in neat logical systems. But this would mean that these "logics" or forms of reasoning could not be evaluated as good or bad since each of them obeys some kind of "logic". Thus, a descriptive view of logic might lead to a kind of logical relativity where each form of reasoning would be as good as any other.

These worries are important methodological issues about the role of logic in experimental philosophical logic. And it is important to address them if we are to see the fruits of projects in this area. Furthermore, addressing these worries might lead to a reflective equilibrium where the descriptive and normative roles are balanced out (Dutilh Novaes 2012, 79).

Some initial steps to address these worries, however, could already be seen in the psychology of reasoning literature. For example, some theorists have suggested distinguishing the normative role of logic (and other normative systems of reasoning, e.g. probability and decision theory) from its prescriptive role. In this prescriptive view, logical theories are seen as reasoning prescriptions for actual, real-life reasoning. The rules of inference embedded in a logical theory are taken not as norms for correct reasoning that cuts across various reasoning contexts; rather, they are taken as guidelines of how to reason in particular reasoning contexts. ${ }^{17}$ For example, instead of thinking of Priest's LP as a universal norm for reasoning, we might take it as a prescription that when we reason about the liar sentence, "This sentence is false," we ought to take it as both true and false. Likewise, if we are dealing with vague sentences, like sentences about future events, we might take Łukasiewicz's L3 as a prescription that we ought to judge them as neither true nor false. Taken this way, each logical system would prescribe correct forms of reasoning in particular contexts. As characterized thus far, the prescriptive role of logic would be a kind of normative logical pluralism, while the normative role would be a kind of normative logical monism. ${ }^{18}$

17 This point, I think, is shared by Dutilh Novaes (2012); see also (Stanovich 1999) and (Bell, Raiffa and Tversky 1988).

18 This point was raised by a referee of this journal. 
But what is going for the prescriptive role of logic is that it has two theoretical merits. First, it recognizes that human reasoners are not ideal rational reasoners. They need to be told how to reason in particular circumstances. In this way, the prescriptive view has sidestepped the issue raised against the normative view. Second, it also recognizes the normative force of logical principles; since prescriptions are context-relative "oughts," they already imply some kind of normative force. In this way, the prescriptive view has also addressed the worry raised against the descriptive view.

One further merit of disentangling the prescriptive role from the normative role of logic is that it gives us a new way of viewing of the interplay between the three roles of logic. Furthermore, we will have an appreciation of the different kinds of projects for experimental philosophers of logic; which further implies different tests of adequacy for these projects.

In assessing logic's normative role, for example, experimental philosophers of logic (and logicians in general) are more concerned with a logical theory's internal, theoretical merits rather than its applications. As such, logicians are more concerned about the theoretical adequacy of the theory, where simplicity, non-ad hocness, etc. would be factors. In assessing logic's descriptive role, on the other hand, experimental philosophers of logic are concerned about the empirical adequacy of a logical theory. That is, their main concern would be how well the theory accounts for the data observed in reasoning experiments. ${ }^{19}$ Finally, in assessing logic's prescriptive role, experimental philosophers of logic are more concerned about the utility or pragmatic value of these reasoning prescriptions. Their main concern would revolve around issues about the applicability of logical devices in specific reasoning circumstances. Thus, in this tripartite view of logic, different roles imply different projects, and different tests for adequacy.

Though adding a prescriptive role to logic might have its merits, it is still susceptible to some other worries. For example, given that logical theories are reasoning prescriptions, there is a worry of how to decide what logical theory should be prescribed in a given reasoning context. Furthermore, there is a worry about who should make such decisions. There is

19 This is, perhaps, one way of appreciating the current literature in the psychology and philosophy of vagueness. 
another more fundamental worry concerning the ad-hocness of the distinction between the normative and prescriptive roles. If this distinction does not hold, then all the merits we have seen would be put into question. These are further challenges that experimentally-inclined philosophers of logic need to meet.

\section{Experimental data and philosophical logic}

Another issue for an experimental approach to philosophical logic is about the role and importance of experimental data in logic itself. Two negative views could be cited here. One comes from L. J. Cohen (1981); the other from Gilbert Harman (1986). ${ }^{20}$ Both imply the independence of experimental data and logic from one another.

Cohen argues that there seems to be a gap between experimental data and logic. Though experimental data might indicate that many reasoners perform poorly in some reasoning tasks, it does not follow that they are incompetent in terms of the implied norms of a given logical theory. The reasoners could just be employing some other system of logic. For example, data from the Wason card-selection experiment have shown that human reasoners are poor at judging conditional statements (Ripley 2016; Joaquin and Agregado 2018). But from these data, Cohen argues, we could not make any evaluation of the adequacy of the implied normative, classical logical system assumed in the experiments since such a logical framework is just assumed by the experimenters. Nor could we make any evaluation of the human subjects' reasoning competencies since the human subjects might just be employing a different rule for conditional reasoning.

In a slightly different angle, Harman seems to echo the same point. We could take him as arguing that since reasoning and logic are about two different things, and are governed by two different sets of considerations, it

20 These two objections are already well-documented in the literature. For example, Evans and Over (1996) discuss Cohen's views extensively; Harman's view of logic and its relation to reasoning, and the commentaries of other philosophers are detailed in (Dutilh Novaes 2015). The discussion here will just highlight the salient points regarding the role of experimental data in logic. 
follows that experimental results about reasoning must be evaluated independent of the correctness of a given logic.

For Harman, logic is concerned with implications, with consequence relations, with what follows from what. For example, in logic, we are concerned with whether some statement, Q, follows from (or is implied by, or is a consequence of) the statements: If $\mathrm{P}$, then $\mathrm{Q}$; and, $\mathrm{P}$. And that's the end of that. Reasoning, on the other hand, is concerned with the reasonability of belief revision, with what he calls, "reasonable change in view." For example, in everyday reasoning, you might infer (in the sense of that you cognitively suppose) that there is milk in the fridge from the fact that you bought one yesterday. However, finding out that there is no milk in the fridge might make you revise some of your starting beliefs. Perhaps, you might now suppose that you forgot to buy milk yesterday, or that you have just misplaced it, or that some extraterrestrial alien took it. Of the three choices here, we might judge the last as the most unreasonable, while the other two as reasonable. Of course, the second would be more reasonable if you find the receipt that proves that you bought milk yesterday. In judging the reasonability of these options, however, logic plays little to no role at all. What is doing the work here has something to do with epistemic considerations about the reliability of our evidence (in the case of the receipt) and some sort of background knowledge (in the case of extra-terrestrial aliens).

For Harman (1986, 11-12), the assessment of the reasonability of some belief, Q, does not stem from the principles of logic. Following the principles of logic, Q might be logically deduced from "If P, then Q" and "P." But even if one believes the starting information and the validity of the inference, one might still not come believe Q. Thus, the assessment of the correctness of a given logical theory seems to be independent of the reasonability of belief revision since the latter is governed by a set of epistemic considerations, which do not really govern the former.

Both Cohen's and Harman's views seem to imply that our evaluation of the actual reasoning performance of human subjects (found in reasoning experiments) must be independent from our evaluation of principles of some given logic. For Cohen, this is so since human subjects might be using a different logic in performing their tasks. For Harman, this is so since reasoning and logic are about two different things. Having said this, it is now useful 
to divide the issue about the role of experimental data in logic into two subissues: first, the issue about their role in pure logic; second, their role in philosophical logic, and see whether both of their views work for these subissues.

At the onset, it would seem that experimental data do not really play any role in pure logic. But this is so independent of the views of Cohen or Harman. Recall that we have characterized works in pure logic as highly abstract, and said that they are more concerned with the formal features of logical systems rather than their applications. Viewed this way, these works are evaluated in terms of their theoretical adequacy much like we assess the normative role of logic discussed above. Furthermore, logicians evaluate a logical theory's elegance and simplicity much like mathematicians judge the elegance and simplicity of mathematical proofs and theories.

Experimental results, on other hand, seem to have a role in philosophical logic given that the canonical application of logic is in the analysis of reasoning. As such, the views of Cohen and Harman might weigh in. To address Cohen's view, an experimental philosopher of logic might reply as follows. Suppose that Cohen is right that human subjects do employ different types of logics in performing reasoning tasks. Then all the more an experimental approach to philosophical logic should be undertaken in order to identify these sorts of logics.

To address Harman's view, on the other hand, our experimental philosopher of logic might reply as follows. Harman is surely wrong that logic is just concerned with (logical) implications since there are other logics, like some non-monotonic logics, which are concerned with belief revision as well [see, e.g., (Dutilh Novaes and Veluwenkamp 2017)]. At least in these types of logics, experimental data are needed as validation. ${ }^{21}$

\section{Two case studies}

As a conclusion, in this final section, we will explore two strands of current work in experimental philosophical logic to illustrate the fruitfulness

21 See (Dutilh Novaes 2015, 590-91) for further clarifications about this matter. See also (Field 2009) for a different reply to Harman. 
of this kind of approach. First, we explore the work done by Dutilh Novaes about the potential prescriptive role that logic plays in the psychology of cognitive biases; second we explore work done in the fast-growing literature on the psychology of vagueness, which takes experimental data to evidence philosophical/logical theories of vagueness. ${ }^{22}$

Dutilh Novaes (2012) investigates the role that formal languages play in the psychology of reasoning, esp. in the psychology of cognitive biases. Cognitive biases are reasoning mistakes that people often commit; they are "systematic errors" which are brought about by our limited cognitive capacities. One particular cognitive bias that she focuses on is belief bias, i.e. the tendency to take logically invalid arguments with believable conclusions as valid.

Belief bias is a well-documented phenomenon in the psychology of reasoning literature. A series of experiments on syllogistic reasoning competence has shown that many people would endorse the validity of a logically invalid syllogism if its conclusion is believable and the concepts used therein are comprehensible. For example, only $32 \%$ of the test subjects endorsed the logically correct indictment (i.e., the argument is invalid) when confronted with this syllogism:

All living things need water. Roses need water. Therefore, roses are living things.

On the other hand, confronted with an argument with the same invalid syllogistic form, but phrased in unknown concepts, viz:

All animals of the hudon class are ferocious. Wampets are ferocious.

Therefore, wampets are animals of the hudon class.

$78 \%$ of the same test subjects gave the logically correct answer (Dutilh Novaes 2012, 94).

Dutilh Novaes conjectured that what is doing the work in the first case is our tendency to have an automatic response to known data; while in the second case it is our tendency to slow down our thinking when it comes to unknown data. In the former case, we are susceptible to belief bias. In the

$22 \quad$ For references, see note 5 . 
latter case, the principles of logic factor in our reasoning process. Furthermore, she suggests that in order to improve our reasoning skills, we ought to take a formal language (like, the language of syllogistic logic) as a tool to counterbalance our default reasoning processes, such as belief bias. In this way, we could interpret Dutilh Novaes as providing a prescriptive role for logic. ${ }^{23}$

If in Dutilh Novaes' work, logic plays a potential prescriptive role, in the works in the logic and psychology of vagueness, logic plays a more descriptive role. Recall that seeing logic in its descriptive role implies seeing it as a kind of study whose primary task is to categorize various types of reasoning in an appropriate formal system. This can be seen in the way the literature on vagueness has developed in the last few years.

Research on vagueness has led to the creation (or discovery) of philosophically interesting logical systems, which aim to explain the phenomenon. But since the 1990's there has been a steady growth of philosophical studies which employed experimental data to evidence logically-couched philosophical theories.

Bonini and his colleagues (Bonini et al. 1999), for example, present experimental results about the use of vague expressions by native Italian speakers, and take the results to count in favor of a "vagueness-as-ignorance" view - an epistemicist theory of vagueness, which tells us that vagueness (i.e., expressions which seem to lack sharp boundaries or have truthvalue gaps) only occurs because we lack the knowledge of the actual boundaries of concepts we employ. In one of their experiments, subjects were tasked to fill-in a questionnaire which tests their judgments about tallness. They were asked questions (in Italian) amounting to:

23 A referee of this journal pointed out that Dutilh Novaes' view seems to imply that a given logic is not an instruction but a tool used to counterbalance our default reasoning tendencies. As such, logic does not really prescribe a set of rules for correct reasoning. I reply, however, that as a tool, logic does come with a prescribed set rules for correct reasoning that may be effectively used in certain reasoning contexts. As Dutilh Novaes $(2012,3)$ tells us, "the historical development of formal languages can be viewed as a process of cultural evolution through which humans looked for tools that would allow them to perform certain tasks and solve certain problems more efficiently [...]." 
A man is tall if his height is greater than or equal to centimeters.

A man is not tall if his height is lesser than or equal to centimeters.

A man is at least of average height among 30-year-old Italians if his height is greater than or equal to centimeters.

Surprisingly, the results have shown that "judgments of the lower threshold it takes to be tall were significantly higher than judgments of the higher threshold it takes to be not tall" indicating truth-value gaps, even though the two latter questions seem to imply the existence of actual boundaries between tall and not tall average 30-year-old Italians.

Several years later, other experimental studies have shown a different and a more paraconsistent-friendly result. For example, Ripley (2011) tested how subjects appreciate and evaluate the vague relational predicate, "near," and found that when it comes to borderline cases, subjects tend to tolerate contradictions of the form, $\mathrm{x}$ is both near and not near to $\mathrm{y}$. The experiment goes this way. Subjects were shown seven pairs of figures (A to G) each consisting of a square and a circle at decreasing distances from each other. The extreme cases, A and G, are clear-cut cases. Case A was a clear case where the square and the circle are far apart, while Case $\mathrm{G}$ shows these figures as clearly close to each other. The less extreme cases, B and F, showcase a little decrease (in the case of $\mathrm{B}$ ) and a little increase (in the case of F) of distances of the figures. And the borderline cases, C to E, are the target cases. Subjects were, then, asked whether they agree that the contradictory sentence "the circle is near the square and it isn't near the square," along with its linguistic variants, is true. What was found is that a significantly greater proportion of subjects fully agree with the contradictory sentence as they approach the borderline cases than for the extreme cases. This evidences a kind of paraconsistent logic, which accepts true contradictions. $^{24}$

Further work in the logic and psychology of vagueness has already been pursued, and has led to the developments of certain logics. For example, Cobreros et al. (2012) have developed a strict-tolerant logic based on three

24 Alxatib and Pelletier (2011) also present the same result, but from a different experimental set-up. 
notions of truth: classical truth, strict truth, and tolerant truth. This logic aims not only to account for vagueness, but also to account for the proffered experimental data. The logic defines up strict truth (akin to Kleene's K3 logic) and tolerant truth (akin to Priest's LP), and shows that experimental results could be explained in terms of these two dual notions.

The field of inquiry into the logical and psychological aspects of vagueness is quite open; and it looks out for new and exciting ways of buildingup the relationship between logic and experiment. But this is not only true of research in vagueness. The interaction between the two might yield more interesting results in areas where reasoning and logic coincide. As one experimental philosopher of logic notes:

We should expect experiment and logic to fruitfully interact whenever a field of inquiry involves rigging up a logical system to capture some experimentally explorable phenomenon; in these cases, logical approaches will help us decide which aspects of the phenomenon to experimentally explore, and experimental approaches will help us choose which logics best capture the phenomenon. (Ripley 2016, 533)

And this is something experimentally-minded philosophers of logic are keen to do and achieve.

\section{Acknowledgements}

A version of this paper was presented at the Australasian Association for Logic 2015 Conference. I would like to thank the participants and organizers, especially Nick J. J. Smith and Simon Varey, for their useful feedback. Special thanks to Hazel Biana, Robert James Boyles, Ben Blumson, David Chalmers, Mark Anthony Dacela, Catarina Dutilh Novaes, James Franklin, Adrianne John Galang, Napoleon Mabaquiao, Graham Priest, and David Ripley for the discussions that helped shape the key themes of this paper.

\section{References}

Alxatib, Sam, and Francis Jeffry Pelletier. 2011. "The Psychology of Vagueness: Borderline Cases and Contradictions." Mind \& Language 26 (3): 287-326. https://doi.org/10.1111/j.1468-0017.2011.01419.x 
Beall, Jeffrey, and Greg Restall. 2006. Logical Pluralism. Oxford: Oxford University Press. https://doi.org/10.1093/acprof:oso/9780199288403.001.0001

Bell, David E., Howard Raiffa, and Amos Tversky, eds. 1988. Decision Making: Descriptive, Normative, and Prescriptive Interactions. Cambridge: Cambridge University Press. https://doi.org/10.1017/CBO9780511598951

Bonini, Nicolao, Daniel Osherson, Riccardo Viale, and Timothy Williamson. 1999. "On the Psychology of Vague Predicates." Mind \& Language 14 (4): 377-93. https://doi.org/10.1111/1468-0017.00117

Braüner, Torben. 2014. "Hybrid-Logical Reasoning in False-Belief Tasks." In Logic and Interactive Rationality, Volume II: Yearbook 2012, edited by Zoé Christoff, Paolo Galeazzi, Nina Gierasimczuk, Alexandru Marcoci, and Sonja Smets, 79-103. University of Amsterdam.

Burgess, John P. 2009. Philosophical Logic. Princeton: Princeton University Press. Cobreros, Pablo, Paul Egré, David Ripley, and Robert van Rooij. 2012. "Tolerant, Classical, Strict." Journal of Philosophical Logic 41 (2): 347-85. https://doi.org/10.1007/s10992-010-9165-z

Cohen, L. Jonathan 1981. "Can Human Irrationality be Experimentally Demonstrated?" Behavioral and Brain Sciences 4 (3): 317-31. https://doi.org/10.1017/S0140525X00009092

Cook, Roy T. 2009. Dictionary of Philosophical Logic. Edinburgh: Edinburgh University Press.

Chalmers, David J. 2007. "X-Phi Meets A-Phi." Talk presented at Experimental Philosophy Meets Conceptual Analysis, slides, URL: http://consc.net/papers/xphi.ppt

Chalmers, David J. 2009. "What can Experimental Philosophy Do?" Talk presented at NEH Institute on Experimental Philosophy, slides, URL: http://consc.net/papers/xphil.ppt

Chalmers, David J. 2012. Constructing the World. Oxford: Oxford University Press. Dutilh Novaes, Catarina. 2012a. Formal Languages in Logic: A Philosophical and Cognitive Analysis. Cambridge: Cambridge University Press. https://doi.org/10.1017/CBO9781139108010

Dutilh Novaes, Catarina. 2012b. "Towards a Practice-Based Philosophy of Logic: Formal Languages as a Case Study." Philosophia Scientiae 16 (1): 71-102. https://doi.org/10.4000/philosophiascientiae.719

Dutilh Novaes, Catarina. 2015. "A Dialogical, Multi-Agent Account of the Normativity of Logic." Dialectica 69 (4): 587-609. https://doi.org/10.1111/17468361.12118

Dutilh Novaes, Catarina, and Erich Reck. 2017. "Carnapian Explication, Formalisms as Cognitive Tools, and the Paradox of Adequate Formalization." Synthese 194 (1): 195-215. https://doi.org/10.1007/s11229-015-0816-z 
Dutilh Novaes, Catarina, and Herman Veluwenkamp. 2017. "Reasoning Biases, Non-Monotonic Logics and Belief Revision." Theoria 83 (1): 29-52. https://doi.org/10.1111/theo.12108

Evans, Jonathan S.B., and David E. Over. 2013. Rationality and Reasoning. East Sussex: Psychology Press.

Field, Hartry. 2009. "What is the Normative Role of Logic?" Proceedings of the Aristotelian Society 83 (1): 251-68. https://doi.org/10.1111/j.14678349.2009.00181.x

Geurts, Bart, and Frans van der Slik. 2005. "Monotonicity and Processing Load." Journal of Semantics 22 (1): 97-117. https://doi.org/10.1093/jos/ffh018

Ghosh, Sujata, Ben Meijering, and Rineke Verbrugge. 2014. "Strategic Reasoning: Building Cognitive Models from Logical Formulas." Journal of Logic, Language and Information 23 (1): 1-29. https://doi.org/10.1007/s10849-014-9196-x Harman, Gilbert. 1986. Change in View. Cambridge, Mass.: MIT Press.

Jacquette, Dale, ed. 2006. A Companion to Philosophical Logic. London: Blackwell Publishing. https://doi.org/10.1002/9780470996751

Joaquin, Jeremiah Joven, and Jose Emmanuel Agregado. 2018. "Grounding Logic: A Reply to Shenefelt and White." Think: Philosophy for Everyone 17 (49): 1316. https://doi.org/10.1017/S1477175618000052

Knobe, Joshua, and Shaun Nichols. 2007. "An Experimental Philosophy Manifesto." In Experimental Philosophy, edited by Joshua Knobe and Shaun Nichols, 3-14. Oxford: Oxford University Press.

Priest, Graham. 2005. Doubt Truth to be a Liar. Oxford: Oxford University Press. https://doi.org/10.1093/0199263280.001.0001

Priest, Graham. 2014. "Revising Logic." In The Metaphysics of Logic, edited by Penelope Rush, 211-23. Cambridge: Cambridge University Press. https://doi.org/10.1017/CBO9781139626279.016

Read, Stephen. 1995. Thinking about Logic. Oxford: Oxford University Press.

Restall, Greg, and Gillian Russell. 2012. New Waves in Philosophical Logic. New York: Palgrave Macmillan. https://doi.org/10.1057/9781137003720

Ripley, David. 2011. "Contradictions at the Borders." In Vagueness in Communication, edited by Rick Nouwen, Robert van Rooij, Uli Sauerland, and HansChristian Schmitz, 169-88. New York: Springer. https://doi.org/10.1007/978-3642-18446-8_10

Ripley, David. 2016. "Experimental Philosophical Logic.” In Blackwell Companion to Experimental Philosophy, edited by Wesley Buckwalter and Justin Sytsma, 523-34. London: Wiley-Blackwell. https://doi.org/10.1002/9781118661666.ch36 Rips, Lance J. 2008. "Logical Approaches to Human Deductive Reasoning." In Reasoning, edited by Jonathan E. Adler and Lance J. Rips, 187-205. Cambridge: Cambridge University Press. 
Roth, Charles H., and Larry L. Kinney. 2014. Fundamentals of Logic Design, $7^{\text {th }}$ edition. Stamford, CT: Cengage Learning.

Russell, Gillian. 2008. "One True Logic?" Journal of Philosophical Logic 37 (6): 593-611. https://doi.org/10.1007/s10992-008-9082-6

Russell, Gillian. 2017. "An Introduction to Logical Nihilism." In Logic, Methodology and Philosophy of Science - Proceedings of the $15^{\text {th }}$ International Congress, edited by Hannes Leitgeb, Ilkka Niiniluoto, Päivi Seppälä, and Elliot Sober, 120-31. London: College Publications.

Sainsbury, Robert Mark. 2001. Logical Forms: An Introduction to Philosophical Logic, $2^{\text {nd }}$ edition. London: Blackwell.

Sainsbury, Robert Mark. 2002. "What Logic Should We Think with?" Royal Institute of Philosophy Supplements 51: 1-17.

https://doi.org/10.1017/S1358246100008055

Sider, Theodore. 2010. Logic for Philosophy. Oxford: Oxford University Press.

Smith, Nicholas J.J. 2008. Vagueness and Degrees of Truth. Oxford: Oxford University Press. https://doi.org/10.1093/acprof:oso/9780199233007.001.0001

Stanovich, Keith. 1999. Who is Rational? Studies of Individual Differences in Reasoning. New Jersey: Lawrence Erlbaum Associates, Inc.

Stenning, Keith, and Michiel van Lambalgen. 2008. Human Reasoning and Cognitive Science. Cambridge, MA: MIT Press.

Stich, Stephen. 1990. The Fragmentation of Reason. Cambridge, MA: MIT Press.

Van Benthem, Johan. 2008. "Logic and Reasoning: Do the Facts Matter?" Studia

Logica 88 (1): 67-84. https://doi.org/10.1007/s11225-008-9101-1

Williamson, Timothy. 1995. Vagueness. London: Routledge. 